\title{
The evolution of postgraduate medical education
}

\author{
D. Innes Williams
}

Director, British Postgraduate Medical Federation 33 Millman Street, London WC 1N 3EJ, UK.

The Fellowship of Postgraduate Medicine was set up after the First World War to facilitate, by the provision of courses, the training both of UK graduates and of those from the Commonwealth who came to seek instruction and experience in Britain. A similar initiative, after the Second World War, emanating from, amongst others, the British Postgraduate Medical Federation, has gradually been replaced by a movement which seeks to achieve for all graduates an ordered progression through approved training posts providing appropriate experience, supplemented by course study and punctuated by diploma examinations and accreditation, to consultant or general practitioner principal status. The movement has been erratic, intermittent, unco-ordinated and the result of the separate endeavours of many different bodies. It is far from complete, but nevertheless the postgraduate scene today presents a widely different picture from the individually contrived and opportunistic ladder of progress climbed by the ambitious young doctor between the wars.

Of the forces involved, the three older Royal Colleges were first in the field, having a well established system of Fellowship and Membership examinations, with a requirement for appropriate experience. Next were the Universities, building from their undergraduate base and acquiring a postgraduate responsibility via two separate strands; the academic structure of professorial departments in Medical Schools and Postgraduate Institutes on the one hand, and the Regional Postgraduate Deans, struggling for some years to establish their role on the other. The third force has been the NHS, primarily concerned with service to patients, but which has, since the mid-1960s, recognized its obligation to train its own staff and has provided much of the financial support required for the postgraduate activities of both the Colleges and the Universities. The great charitable Trusts, the Nuffield, King's Fund, and others, have been active in guiding and stimulating improvement and in regard to resources one cannot ignore the contribution of the pharmaceutical industry.

Several attempts have been made at the co-ordina-

Sir David Innes Williams, M.D., M.Chir., F.R.C.S. tion of these separate interests, none as yet wholly successful. The Councils for Postgraduate Medical Education, set up in 1971, bring representatives of all parties around one table and have achieved a small measure of consensus in some spheres, while the General Medical Council, given by the Medical Act of 1978 a responsibility for the co-ordination of all stages of medical education, has yet to find a method of securing acceptance for its policies. A chronological account of medical education in the past forty years inevitably highlights the interaction of all these institutions.

The British Postgraduate Medical Federation, set up by the University of London in 1945 and receiving its Charter two years later, brought together what was then the Postgraduate Medical School at Hammersmith Hospital with the Institutes then set up in each of the long-established specialist hospitals in London, thirteen in all, the largest being at the Maudsley, the Royal Cancer Hospital, Moorfields, the Hospital for Sick Children, Great Ormond Street, the Brompton, and the National Hospital, Queen Square. The Federation thus complemented and extended the work of the medical schools and it in this respect was concerned with the education of future academic clinicians and of specialist consultants. But Sir Francis Fraser, the first Director, had a far wider concept of the needs of modern medicine and sought to establish by his own initiative in the four Metropolitan Regions and by example in the rest of Britain a co-ordinated Regional structure of postgraduate education. Thus, immediately after the war, demobilized medical officers were offered a range of supernumerary posts in teaching and other hospitals and the nascent BPMF acted on behalf of the University in these arrangements, which reached their peak in 1948. From this grew an organisation of Regional Postgraduate Committees in the Metropolitan Regions, served at first by Advisers, later designated Deans, which sought to assess the work of the non-teaching hospitals in providing suitable registrar posts for specialist training, but also with a view to their ability to run postgraduate courses of lectures which were then seen as the appropriate vehicle of education both for the general practitioners and intending specialists.

In 1950 the Medical Act first made it obligatory for new graduates to undertake a year of 'pre-registration' 
internship. The Universities were given the responsibility, which they allotted to the Postgraduate Deans, of finding and supervising suitable posts, while the Medical School Dean retained the authority to certify to the General Medical Council the satisfactory completion of this stage of training. It has to be allowed that University supervision was at first perfunctory and this activity did not immediately lead the Postgraduate Deans to exercise any wider role, which they subsequently acquired, in the oversight of training in other junior hospital posts. Here the Colleges played an important part, the Royal College of Surgeons and the Royal College of Obstetricians and Gynaecologists having a long tradition of inspection of posts deemed fit to provide appropriate experience to candidates for the Fellowship or Membership. The Royal College of Physicians later followed suit. College diplomas, the examinations, and the standards set by them were then central to much of postgraduate endeavour throughout the early years. They still remain obligatory for hospital specialists and the higher degrees of the University now represent only the product of research activity. Nevertheless, the College diplomas were gradually relegated to the status of entrance examinations for higher specialist training, in which a structured programme of experience at senior registrar level in various aspects of the chosen specialty led to accreditation. Higher specialist training evolved first in the surgical specialties and was essentially an initiative of the Royal Colleges, although nominally the Universities and specialist Associations played an important part. The system has been taken up with slightly less enthusiasm by the physicians and by the newer Royal Colleges of Psychiatry, Radiology and Pathology, while the Regional Deans, who have had little part in the construction of the programmes, have come to assume an important role in the supervision of individual senior registrars and of their relationship to Health Authorities.

On the Regional side, the Christchurch Conference (Oxford) convened by the Nuffield Provincial Hospitals Trust in 1961 was a significant landmark. It established the principle that all doctors should have postgraduate education at the same time as occupying posts in hospital, and it did a lot to stimulate the setting up of Postgraduate Centres in District General Hospitals. These Centres were at first financed from voluntary sources and throughout their development the drug companies have played an important part in their support. Only later did the Health Authorities undertake not only the capital cost of that development but the running costs of the Postgraduate Centre Secretary and the very necessary library. Even now, there are many Districts still lacking a Postgraduate Centre, which should form the educational focus for the junior hospital staff and hopefully also for local general practitioners.

Postgraduate Centres cannot function, however, $\bar{z}$ without the oversight and the initiative of the Clinical $\stackrel{\mathbb{Q}}{\mathbb{Q}}$ Tutors, recruited from amongst the hospital consul- $c$. tants, receiving their appointment, although rather $\Rightarrow$ remotely, from the University authority, and rewar- $\frac{0}{+}$ ded only by a very modest honorarium. Nevertheless, the Regional Deans, working together with the Clin- $\frac{\bar{N}}{\bar{N}}$ ical Tutors and an increasingly numerous body of $\frac{\infty}{\sigma}$ unpaid specialist Tutors in each of the Regions, are $\stackrel{\varnothing}{\Omega}$ forming a network of educational administration $\%$ throughout the District General Hospitals. It was only $\vec{\circ}$ after the Todd Report in 1968 that all hospital junior posts were officially recognized as training posts and $\vec{\omega}$ only in 1972 that an agreement between the Health $\frac{\text { s }}{8}$ Departments and the University Grants Committee 00 was reached, by which the Universities would be responsible for the appointment of the Regional $\rightarrow$ Deans and their staff but the expenses of these officers and of the courses which they put on should be met by the Regional Health Authority.

Progress in the field of education for general $\vec{\partial}$ practice has been even more remarkable. In the early $\frac{5}{5}$ post-war years, the British Postgraduate Medical $\vec{\overrightarrow{ }}$ Federation put on a number of courses of lectures intended for general practitioners, while at the start of $\frac{0}{0}$ the Health Service the Ministry introduced the trainee $\stackrel{\mathbb{D}}{\stackrel{9}{-}}$ general practitioner scheme for which the BPMB $\vec{\phi}$ organised courses for selected general practitione of trainers. The scheme foundered, however, as too man trainees were used simply as assistants, and generat practice seemed to be in the doldrums. However, with the establishment of the Royal College of General Practitioners and the publication of its Charter for Family Practice, a resurgence began and since the general practitioners were able to make a fresh start there has perhaps been more innovative thinking in this area than in some recent discussions of postgraduate hospital medicine. The Health Services and Public Health Act of 1968 set up, under Section 63, the provision of funds for the continuing education of general practitioners, which enabled Postgraduate Centres to put on appropriate courses. At one time, seniority payments to practitioners were dependent upon attendance at such courses, and when this system was discontinued in 1977 numbers signing on fell. The view is often expressed that teaching by hospital $\rightarrow$ consultants is not what general practitioners need, greater success being achieved by small groups run and $N$ taught by the practitioners themselves with minimal specialist in-put. Regional Advisers in General Practice were appointed to assist the Regional Postgraduate Deans from the early 1970 s and have been concerned with the identification of trainers. The $Q$ National Health Service (Vocational Training) Act of $\mathbb{D}$ 1976 laid down a programme of two years' hospital experience in an assortment of specialty posts, foll- 
owed by a year of traineeship in general practice, as the essential requirement for a newly appointed Principal in general practice. This part of the profession has been alone in choosing a statutory mechanism for ensuring adequate postgraduate training, as was inevitable from the independent contractor status of the general practitioner. The effects of the 1976 Act are only now becoming evident, but the enhanced status of practice has drawn into it a high proportion of the best graduates of the UK medical schools.

It is evident then that considerable progress has been made towards a structured programme of postgraduate education for all doctors, but stability has not yet been reached. In recent years the cut-back in University and in NHS funding has led to diminished resources for education, while the problems of manpower and the excessive proportion of junior staff in the most popular hospital specialties lead to great uncertainty. The academic departments of the teach- ing hospitals have suffered staff reductions affecting postgraduate research work; five of the smaller Institutes of the British Postgraduate Medical Federation are due to be merged with Undergraduate Schools in the next two years, and the Royal Postgraduate Medical School, now independent from the Federation, although maintaining its remarkable academic record, has suffered great financial stringency. The future of the overseas doctors who have come in such large numbers to Britain for training but have sometimes remained to take senior posts in the NHS is uncertain. It seems inevitable that it will be necessary to curtail either their numbers or their length of stay in order that reasonable opportunities can be provided for their training. This and the medical manpower issue make it inevitable that postgraduate medicine becomes involved, along with the future of the Health Service, in a major political struggle. 